\title{
Midiatização: um conceito, múltiplas vozes
}

\section{Midiatization: a concept, multiple voices}

\author{
Pedro Gilberto Gomes \\ Mestre e Doutor em Ciências da Comunicação pela Escola de Comunicação e Artes da Universidade de São Paulo. Professor \\ Titular do Programa de Pós-Graduação em Ciências da Comunicação. Linha de pesquisa: Midiatização e Processos Sociais. \\ Pesquisador com Bolsa PQ2 do CNPq. \\ <pedrogilberto28@hotmail.com>
}

\section{RESUMO}

A midiatização tornou-se cada vez mais um conceito chave, fundamental, essencial para descrever o presente e a história dos meios e a mudança comunicativa que está ocorrendo. Desse modo, se se tornaram parte do todo, não se pode vê-los como uma esfera separada. Nessa perspectiva, a midiatização é usada como um conceito para descrever o processo de expansão dos diferentes meios técnicos e considerar as inter-relações entre a mudança comunicativa dos meios e a mudança sociocultural. Entretanto, muito embora vários pesquisadores utilizem o conceito de midiatização, cada um Ihe dá o significado que melhor Ihe agrada. Desse modo, o conceito de midiatização é tratado com múltiplas vozes. O presente texto procura discutir esse problema e apresentar uma posição preliminar sobre o assunto.

Palavras-chave: Comunicação. Midiatização. Mapa sistêmico.

\begin{abstract}
Midiatization has become increasingly a key concept essential to describe the present and the history of media and communicative change taking place. Thus, it became part of the whole, one can not see them as a separate sphere. In this perspective, the media coverage is used as a concept to describe the process of expansion of the different technical means and consider the interrelationships between the communicative change in the means and the sociocultural change. However, although many researchers use the concept of midiatization, each gives you the meaning that best suits your needs. Thus, the concept of media coverage is treated with multiple voices. This paper discusses this problem and present a preliminary preposition on the matter.
\end{abstract}

Keywords: Comunication. Midiatization. Sistemic map.

\section{O problema}

A midiatização tornou-se cada vez mais um conceito chave, fundamental, essencial para descrever o presente e a história dos meios e a mudança comunicativa que está ocorrendo. Desse modo, se se tornaram parte do todo, não se pode vê-los como uma esfera separada. É necessário desenvolver uma compreensão de como a crescente expansão dos meios de comunicação muda nossa construção da cultura, da sociedade e das diferentes práticas sociais. Nessa perspectiva, a midiatização é usada como um conceito para descrever o processo de expansão dos diferentes meios técnicos e considerar as interrelações entre a mudança comunicativa dos meios e a mudança sociocultural. 
Coerente com isso, nos últimos 12 anos, venho realizando uma série de trabalhos, apoiados pelo CNPq, que na sua dinamicidade desembocaram na preocupação com o problema da midiatização.

No final de cada um deles, encontramos o que chamamos de "achados" e "perdidos", sendo esses últimos mais importantes que os primeiros, uma vez que foram eles que deram pistas para chegarmos ao estágio atual.

A questão da midiatização, consequentemente, foi se afirmando na sociedade, tanto no âmbito nacional como internacional, como um objeto fundamental para o trabalho dos pesquisadores que atuam na área da comunicação. Pesquisadores de muitas escolas e das mais variadas regiões geográficas, por caminhos diversos e com pontos de partida distintos, arribaram à praia da midiatização como um conceito fundante para a compreensão do que está acontecendo hoje na sociedade.

Até agora, contudo, os estudos sobre midiatização ocuparam-se com as transformações sociais e culturais nas culturas e sociedades ocidentais. Entretanto, o processo de midiatização também se manifesta (torna-se visível) noutras partes do mundo, exibindo diferentes dinâmicas e possuindo outras consequências em diferentes contextos sociais e culturais ${ }^{1}$.

Será que a midiatização constitui um processo global de mudança? Em caso afirmativo, pergunta-se onde estão localizadas as desigualdades e as dissemelhanças desse processo ${ }^{2}$ Como a midiatização não se apresenta da mesma forma para todos e em todos os lugares, podem existir diferenças e semelhanças entre as culturas e nações em processo de midiatização. Por isso, ela participa da comparação entre os meios e as pesquisas sobre comunicação, não somente no momento atual, mas também numa perspectiva histórica. É fundamental que se pense que diferenças transcultural e transnacional existem e como compará-las entre si. Aqui há o desafio de realizar um trabalho comparativo para separar os diferentes aspectos da midiatização ${ }^{3}$.

Neste trabalho, vamos utilizar o conceito de "midiatização" como um paradigma para analisar e compreender a realidade contemporânea. Há um

1 Essa realidade pode ser observada nas convulsões que estão abalando o mundo árabe e também as mudanças que ocorrem na China. A abertura para o estudo em outras tradições culturais pode ser observada na publicação Communication Research Trends, que publicou um número monográfico ( $v$. 31, n. 1, 2012) sobre: Theological and Religious Perspectives on the Internet. Além da Igreja Católica, são estudados o Judaísmo (Jewish Cyber-Theology), o Islamismo (Islam and Islamic Teaching Online) e o Hinduísmo (Hinduism and the Internet).

2 Tal preocupação aparece nos estudos sobre a economia política da comunicação e também na defesa que se faz do Sul frente ao poder hegemônico do Norte.

3 Este é o desafio que se nos apresenta hoje, impondo a necessidade de uma pesquisa comparativa mais abrangente. 
processo novo, através da proliferação das mídias sociais, potencializadas pela cultura digital, que resiste às abordagens setoriais, até agora levadas a cabo pela academia. Impera a necessidade de um conceito que, abrangente, consiga dar conta do que está acontecendo e possibilite uma abordagem sistêmica para além dos meios particulares. Na nossa formulação, um paradigma que torne possível uma reflexão meta-midiática.

Para tentar dar conta do comedido, realizamos uma análise da realidade que abrange a explicitação da gênese do conceito. Após, examinamos a realidade pensada antes da tematização desse conceito. Para isso, retrocedemos aos anos de 1940, deixando-nos impregnar pelas reflexões do jesuíta francês Pierre Teilhard de Chardin até os nossos dias.. Finalizaremos com tentativa de formular uma opinião preliminar para ser discutida nos diversos níveis da academia.

\section{A análise: a gênese do conceito}

Antes de avançarmos na consideração dos avanços nas pesquisas conceituais sobre o fenômeno da Midiatização, convém perguntar sobre como ele surgiu na descrição da realidade da comunicação e o que ele, etimologicamente, significa ${ }^{4}$.

À guisa de introdução, constatamos que ele está relacionado com o conceito de mídia, que chegou até nós mediado pelos Estados Unidos. É um neologismo, pois, na sua origem, é apenas o plural de "medium", termo latino que significa meio. Nesse caso, o plural é "media". Nos Estados Unidos, a pronúncia é "mídia" e se difundiu como sinônimo de cada meio em particular. Daí que, na publicidade, fala-se de mídia impressa, mídia televisionada, mídia eletrônica etc.

Sobre esse assunto, Marcondes Filho relaciona o termo como importante e decisivo. Constata que o termo é originário da física. "Ele mesmo não é percebido, mas permite a percepção, quer dizer, transmite as características de um objeto sem alterá-lo. Todas as modalidades acontecem num suporte, 0 médium" (Marcondes Filho, 2005, p. 8).

Portanto, muito mais que referido a instrumentos, o medium assemelhase mais com uma ambiência. Essa é a compreensão do termo na física que pode ser, analogicamente, aplicada ao conceito de midiatização.

Concluindo, Marcondes Filho afirma:

Por isso, também se faz mister manter o termo meio, quer dizer, medium (e seu plural media), por possuir uma ligação visceral com

4 Esta preocupação também foi tratada por Bastos (2012). 
a origem dos processos comunicacionais. Comunicação é isso que viabiliza, que dá suporte, que permite a produção de conteúdos (formas). Ela é medium e os diversos suportes comunicacionais, os media, jamais esse termo inculto, testemunho de nossa indigência intelectual, o desastroso neologismo mídia (Marcondes Filho, 2005, p. 8).

Desse modo, sublinha Marcondes Filho, que os meios de comunicação funcionam como medium e se utilizam dos diversos media. Entretanto, a realidade mostra-nos que foi assumido, nos diversos contextos, o termo mídia para significar a totalidade dos meios. Por consequência, esse termo deu origem ao conceito de midiatização. Nesse sentido, considerando que Marcondes Filho o vincula ao contexto da física, talvez se possa, em lugar de renegar, assumir o termo mídia numa perspectiva diferente. Com ela, avançaríamos para o conceito de midiatização para além da consideração dos meros dispositivos tecnológicos de comunicação. Mesmo que alguns pesquisadores, tendo em vista essa discussão, preferem trabalhar com o termo mediatização e outros, ainda, utilizem-se indistintamente dos dois termos, considerando que significam a mesma coisa.

\section{A realidade antes do conceito}

O processo de midiatização da sociedade já era tematizado muito antes de sua conceituação e se tornado visível objeto de preocupação da academia no final do século XX. O rápido desenvolvimento dos instrumentos de comunicação, principalmente depois da eletricidade, suscitou reflexões tanto otimistas como pessimistas por parte de pensadores insignes do século. Não é o propósito aqui visitar a todos, mas apenas aqueles que, no nosso entender, conseguiram tematizar com mais precisão o que estava acontecendo.

\section{Pierre Teilhard de Chardin}

O primeiro que visitaremos, o pensador francês Teillhard de Chardin ${ }^{5}$, postula um processo de unificação da humanidade que pode, analogicamente, ser comparado ao processo de midiatização da sociedade. Para ele, a história é um contínuo processo de unificação rumo à planetarização.

A produção de Teilhard de Chardin é vasta e abrangente. Entretanto, para o que aqui interessa, basta o seu livro sobre o futuro do homem. Numa série

5 Pierre Teilhard de Chardin, jesuíta francês, morreu em 1955, nos Estados Unidos, está na base do pensamento de Herbert Marshall McLuhan. Sua obra seminal é O Fenômeno Humano, publicado em Madrid, pela editora Taurus. 
de conferências publicadas ao longo da década de 1940, Teilhard traça uma linha de reflexão que procura compreender para onde caminha a humanidade, tendo em conta o crescimento populacional e o desenvolvimento científico e tecnológico.

Diz Teilhard:

Uma primeira coisa que nos faz refletir, quando observamos ao nosso redor os progressos da coletivização humana, é o que chamaria o carácter inelutável de um fenômeno que é resultado imediato e automaticamente do encontro de dois fatores igualmente estruturais: por um lado, a superfície fechada da Terra; e por outro, a incessante multiplicação, sobre esta extensão fechada, de unidades humanas dotadas (como consequência dos meios de comunicação cada vez mais rápidos [grifo nosso]) de um raio de ação rapidamente crescente, sem contar que são eminentemente capazes de influenciar-se e interpenetrar-se umas às outras, por causa de seu elevado psiquismo. Sob o jogo combinado desses dois componentes naturais opera-se forçosamente uma espécie de retomada em massa da humanidade sobre si mesma (Chardin, 1962, p.142).

Desse modo, pergunta:

A humanidade, nascida sobre o planeta e espalhada por todo ele, não está formando, pouco a pouco, ao redor de sua matriz terrestre, nada mais que uma só unidade orgânica maior, fechada sobre si mesma, uma só arquimolécula hipercomplexa, hipercentrada e hiperconsciente, co-extensiva ao astro sobre o qual nasceu? O fechamento deste circuito esférico pensante: não será precisamente o que está sucedendo neste momento? (Chardin, 1962, p. 43).

Dentro do problema que nos desafia hoje, esse processo cósmico maior estamos chamando de "processo de midiatização da sociedade". Isso vem explicitado por Teilhard quando afirma:

SobreasuperfíciegeometricamentelimitadadaTerra, constantemente encolhidas pelo acréscimo de seu raio de ação, as partículas humanas não só se multiplicam cada dia mais, mas, por reação a suas mútuas fricções, desenvolvem ao seu redor, automaticamente, uma madeixa cada vez mais densa de conexões econômicas e sociais. Ainda mais: exposta cada uma delas, até seu âmago, às inumeráveis influências espirituais emanadas a cada instante do pensamento, da vontade, das paixões de todas as demais, encontram-se constantemente submetidas interiormente a um regime forçado de ressonância. (...) não está evidente que uma só direção permanece aberta ao movimento que nos arrasta: o de uma unificação sempre crescente? 
(...) Ao mesmo tempo em que a Terra envelhece, mais rápido se contrai sua película vivente" (Chardin, 1962, p. 157).

No caso do ser humano, sublinha, igualmente, sua ascensão psíquica correlativa à socialização pela memória coletiva, na qual se acumula, via experiência, e se transmite, por meio da educação, a herança geral da humanidade. A transmissão cada vez mais rápida do pensamento está possibilitando o desenvolvimento de uma verdadeira rede nervosa que está envolvendo a superfície inteira da terra. Constata, outrossim, que há uma emergência, por meio de uma concentração avançada dos pontos de vista individuais, de uma faculdade de visão comum que se funde, indo além do Mundo contínuo e estático das representações comuns, num universo fantástico de energia atomizada (Chardin, 1962, p. 162).

Será que essa rede nervosa poderia ser identificada ao que chamamos hoje de midiatização? De modo analógico, pode-se dizer que a rede de Internet, com a televisão e os satélites, configura a unificação planetária pensada por Teilhard, ainda que ele tenha falado desde o ponto de vista da biologia? Braga sugere que se poderia pensar a comunicação como superação do biológico6.

Entendemos que o processo de midiatização da sociedade desencadeia um dinamismo que faz com que a humanidade se volte sobre si mesma, como um conjunto unificado de consciências. Aqui entram os meios de comunicação, referidos por Chardin, quando afirma:

\begin{abstract}
Aqui, naturalmente, penso, em primeiro lugar, na extraordinária rede de comunicações radiofônicas e televisivas que nos ligam a todos, atualmente, numa espécie de co-consciência etérea, antecipando talvez uma sintonização direta dos cérebros mediante as forças ainda desconhecidas da telepatia. Mas penso também na insidiosa ascensão destas máquinas surpreendentes de cálculo que, graças a sinais combinados, e na razão de várias centenas de milhares por segundo, não só vêm aliviar nosso cérebro de um trabalho irritante e exaustivo, mas, também, porque aumentam em nós o fator essencial (...) da velocidade do pensamento, está preparando uma revolução no campo da pesquisa (Chardin, 1962, p. 162).
\end{abstract}

Chardin critica severamente os céticos quando chama a atenção para o fato de que todos esses progressos sofreram a ironia de certa filosofia. Os meios

6 Conforme artigo a ser apresentado na UFMG, intitulado: "A imitação é o grau zero da comunicação", onde o conceito de imitação faz a passagem do biológico ao comunicacional. 
são considerados máquinas comerciais para pessoas apressadas para ganhar tempo e dinheiro. Esses críticos são cegos que não percebem

\begin{abstract}
que estes instrumentos materiais, inelutavelmente ligados uns aos outros, em sua manifestação e em seu desenvolvimento, não são, afinal, senão as linhas de uma espécie particular de supercérebro, capaz de elevar-se até dominar algum super campo no Universo e no pensamento" (Chardin, 1962, p. 162).
\end{abstract}

Como vemos, muito embora o conceito não esteja explicitado tal como se entende hoje, Teilhard coloca o mundo numa constante evolução em direção de uma maior complexidade, no que chama de planetarização. Nesse processo, situa a existência e o papel dos meios de comunicação.

O que o mundo contemporâneo está vivendo, na sua radicalidade, não esteve no horizonte de Teilhard de Chardin. A sua preocupação era o movimento em direção à unidade total com Cristo, para além do mundo físico, para a noosfera. Seu ponto de partida foi o mundo biológico. Sua busca era a evolução da humanidade em vista de uma maior complexidade da consciência. Tudo concorria para essa evolução, também os meios de comunicação e a tecnologia nascente. Contudo, será de bom alvitre não deixar de lado seus conceitos fundamentais quando, via tecnologia da informação e da comunicação, se procure interpretar o mundo dos processos midiáticos e uma sociedade em vias de midiatização.

\title{
Marshall McLuhan
}

A posição de Teilhard de Chardin, vista acima, encontra eco e está na base das ideias de Marshall McLuhan, outro pensador seminal para se compreender o que se passa no mundo hoje. Por isso, Tom Wolfe (2005), falando de McLuhan, diz: "Aqui vemos a sombra de uma intrigante figura que influenciou McLuhan tanto quanto Harold Innis, mas a quem ele nunca se referiu de maneira explícita: Pierre Teilhard de Chardin" (Wolf, 2005, p. 16).

Wolf explicita que, para Teilhard, "Deus estava dirigindo o século XX, a evolução do homem para a noosfera (...) uma unificação de todos os sistemas nervosos humanos, todas as almas humanas, por meio da tecnologia" (Wolf, 2005, p. 17).

Constata, outrossim, que o jesuíta francês mencionou "o rádio, a televisão e os computadores em especial com pormenores consideráveis, e alude à cibernética. (...) Esta tecnologia estava criando um "sistema nervoso para a humanidade", escreveu ele, "uma membrana única, organizada, inteiriça sobre a 
terra", "uma estupenda máquina pensante". (...) "A era da civilização terminou", e a da "civilização unificada está começando" (Wolf, 2005, p. 17).

Wolf identifica a noosfera, a membrana inteiriça com a rede inconsútil de McLuhan. Para ele, a civilização unificada não é outra coisa que a aldeia global de pensador canadense. Para corroborar a sua posição, Wolf cita:

\begin{abstract}
Podemos pensar (...) que essas tecnologias são "artificiais" e completamente "exteriores aos nossos corpos", mas, na realidade, elas são parte da evolução "natural, profunda", do nosso sistema nervoso. "Podemos pensar que estamos apenas nos divertindo", ao usá-las, "ou apenas desenvolvendo o nosso comércio, ou apenas propagando ideias. Na realidade, o que estamos fazendo é nada menos do que continuar num plano superior, por outros meios, a obra ininterrupta da evolução biológica. Ou, para dizer de outro modo, afirma Wolfe:"O meio é a mensagem" (Wolf, 2005, p. 18).
\end{abstract}

O pensamento de Marshall McLuhan pode ser acompanhado na sua obra sobre os meios de comunicação como representando extensões do ser humano. O prefácio de seu livro mais conhecido (1996) traz algumas considerações sobre o estado atual em que se encontra a humanidade - a era da eletricidade. Essa nova configuração social traz novos problemas a serem pensados. Um deles é o da ação, que na idade elétrica ganha poder elevado e consigo carrega o problema da angústia, pois nos encontramos novamente tribalizados e muitas de nossas ações têm efeitos imediatos e globais. Segundo McLuhan, depois de três mil anos de evolução, o mundo ocidental está implodindo por causa das tecnologias mecânicas fragmentárias.

$\mathrm{Na}$ idade da mecânica, a humanidade projetou seus corpos no espaço. Hoje, em virtude da tecnologia elétrica, é o sistema nervoso central que é projetado, num abraço global, abolindo espaço e tempo. A simulação tecnológica da consciência está pondo fim às extensões do homem. Por ela, o processo criativo de conhecimento se estenderá por meio dos diversos veículos (McLuhan, 1996, p.17).

Quando a sociedade vivia na idade mecânica, a lentidão dos movimentos retardava a reação, por grandes intervalos de tempo, que muitas ações empreendidas suscitavam. Hoje, tudo acontece quase ao mesmo tempo: ação e reação7. Vivemos como que miticamente e integralmente, mas continuamos a pensar dentro dos velhos padrões da idade pré-elétrica e do espaço e tempo

$7 \quad$ Na economia digital, esta realidade se torna muito mais real. A interação que se dá por meio das redes sociais atinge velocidades antes não imaginadas. $\mathrm{O}$ usuário de uma rede reage imediatamente ao que é postado. 
fracionados (McLuhan, 1996, p. 17). Desse modo, na era da eletricidade as pessoas devem envolver-se profundamente em cada uma de suas ações. Pois, o nosso sistema nervoso central é tecnologicamente projetado para envolver-nos na Humanidade inteira, incorporando-a em nós (Cf. McLuhan, 1996, p. 17).

Dentro dessa perspectiva, ele afirma que o meio é a mensagem. Ora, dizer que o meio é a mensagem

apenas significa que as consequências sociais e pessoais de qualquer meio - ou seja, de qualquer uma das extensões de nós mesmos constituem o resultado do novo escalão introduzido em nossas vidas por uma nova tecnologia ou extensão de nós mesmos (McLuhan, 1996, p. 21).

Não é o uso que se faz de uma máquina que gera os efeitos mais notáveis numa sociedade, mas sim o próprio fato de se usar tal máquina. A técnica da fragmentação, instaurada com a tecnologia da máquina, produziu efeitos nos modos de associação e de trabalho humano, exemplifica o autor. Esclarece, também, que o"conteúdo de qualquer meio ou veículo é sempre um outro meio ou veículo" (McLuhan, 1996, p. 22), o que se assemelha a afirmar que qualquer meio é conteúdo.

A luz elétrica merece de McLuhan um lugar especial. Ela não é percebida como um meio de comunicação porque não possui conteúdo. Ela é somente compreendida como um meio de comunicação quando é utilizada no registro do nome de algum produto. Entretanto, o que aqui se percebe não é a luz, mas o conteúdo. Aqui reside uma falha no estudo dos meios.

\footnotetext{
A mensagem da luz elétrica é como a mensagem da energia elétrica na indústria: totalmente radical, difusa e descentralizada. Embora desligada de seus usos, tanto a luz como a energia elétrica eliminam os fatores de tempo e espaço da associação humana, exatamente como o fazem o rádio, o telégrafo, o telefone e a televisão, criando a participação em profundidade (McLuhan, 1996, p. 23).
}

Tais consideraçõesqueafirmam seromeioa mensagem sãomuito propícias ao estudo sobre a midiatização. Como já foi dito em outras oportunidades, não se trata mais de um questionamento sobre a utilidade dos meios para a transmissão das mensagens, trata-se, na sociedade contemporânea midiatizada, de uma reflexão sobre os próprios meios - os dispositivos tecnológicos - como mensagens e sobre a ambiência em que nos encontramos, permeada por estes dispositivos e suas intervenções. 
Vale ressaltar sua constatação sobre a invasão tecnológica e seus efeitos. Para ele, em nosso ambiente letrado, não estamos mais preparados para enfrentar o rádio e a televisão (diria hoje, a internet, as redes sociais) do que o nativo de Gana quando se encontra com a escrita que o expulsa do seu mundo tribal e o reduz ao isolamento individual. Estamos tão entorpecidos em nosso novo mundo quanto o nativo invadido por nossa cultura escrita mecânica (McLuhan, 1996, p. 31).

Destaque-se a ideia concernente à contração ou implosão do mundo. Para McLuhan, não é o aumento populacional que preocupa, mas o fato de todo mundo estar passando a viver mais contiguamente, fruto do envolvimento elétrico que enreda as vidas umas nas outras (McLuhan, 1996, p. 53). A ampliação da complexidade das coisas implica um forte processo de experimentação interacional.

A sociedade ocidental homogeneizou-se com a alfabetização, simplificouse, de certa forma, enquanto muitos povos orientais permaneceram no rico e heterogêneo âmbito da oralidade. $E$, em relação aos rumos da sociedade atual, vale citar que

a perspectiva imediata para o homem ocidental, letrado e fragmentado, ao defrontar-se com a implosão elétrica dentro de sua própria cultura, é a de transformar-se rápida e seguramente numa criatura profundamente estruturada e complexa, emocionalmente consciente de sua total interdependência em relação ao resto da sociedade humana (McLuhan, 1996, p. 69).

Entretanto, precisamos; essa interdependência não se estabelece sem um enfrentamento de extraordinários desafios. E neste ponto, McLuhan traz outra questão também refletida por Chardin: "O individualismo fragmentado, letrado e visual não tem mais lugar numa sociedade que implode, eletricamente estruturada. O que deve então ser feito?" (McLuhan, 1996, p. 70).

Em relação a hibridizações dos meios mais atuais, o autor traz como exemplo a luz elétrica, que aboliu as fronteiras entre noite e dia, exterior e interior. Quando a luz se encontra com a organização humana, é liberada uma energia que ele chama de híbrida. Carros viajam à noite, espetáculos esportivos podem ser noturnos. Modernos edifícios dispensam janelas. “Numa palavra, a mensagem da luz elétrica é a mudança total. É a informação pura, sem qualquer conteúdo que restrinja sua força transformadora e informativa" (McLuhan, 1996, p. 71). 
Em uma análise das relações de poder, McLuhan afirma que os donos, os que operam os meios, sabem do poder do meio em relação ao conteúdo, ou seja, se preocupam muito mais com a detenção destes meios do que com seus conteúdos.

Voltando à reflexão sobre a hibridização, McLuhan explicita

que os meios, como extensões de nossos sentidos, estabelecem novos
índices relacionais, não apenas entre os nossos sentidos particulares,
como também entre si, na medida em que se inter-relacionam. O
rádio alterou a forma das estórias noticiosas, bem como a imagem
fílmica, com o advento do sonoro. A televisão provocou mudanças
drásticas na programação do rádio e na forma das radionovelas
(McLuhan, 1996, p. 72).

Dentro da visão e dos objetivos que se buscam, questiona-se sobre a forma como a internet interfere nos outros meios e de que forma a midiatização, a sociedade em rede, interferem em nossos sentidos particulares. A questão da tecnologia traz elementos para a reflexão, pois compara as tecnologias anteriores e as que vêm sendo desenvolvidas na era da eletricidade.

Pode-se interpretar as palavras de McLuhan como favoráveis ao pensamento de que, com a eletricidade, de fato, as tecnologias dão um salto qualitativo em relação às produzidas anteriormente. Devemos nos questionar se a era seguinte, na qual nos encontramos - a era digital - representa um salto tão potente em relação à eletricidade quanto esta representou com o seu advento. Uma fase, mesmo qualitativamente superior à anterior, utiliza-se dessa como plataforma para se estabelecer. Por sua vez, ela será plataforma para a fase que a supera. Portanto, a superação de uma fase não significa o seu aniquilamento. Ela permanece na nova situação. Isso se pode ver na relação da oralidade com a escrita, com a imprensa e com os meios eletrônicos.

Nessa linha, McLuhan sublinha que a tecnologia é um modo de traduzir uma espécie de conhecimento para outra, sendo que a tradução é um desvendamento de maneiras de conhecimento. Assim acontece com a mecanização, onde a natureza e as nossas próprias naturezas são traduzidas para formas mais amplas especializadas. Para ele, a primeira tecnologia foi a palavra falada, que possibilitou aos seres humanos desvincularem-se do seu ambiente e retomá-lo de modo novo. As palavras permitem recuperar uma informação que pode abranger a alta velocidade, a totalidade do ambiente e da experiência. Sistemas complexos de metáforas e símbolos, as palavras traduzem a experiência para nossos sentidos. Assim, são uma tecnologia de explicitação. 
A totalidade do mundo é evocada e recuperada a qualquer momento por meio da experiência sensória imediata em símbolos vocais.

Esta experiência sensória sofre uma fragmentação quando da invenção da escrita, que quebrou a hegemonia tribal. $O$ processo iniciado encontrou sua plenitude com a invenção da imprensa, com o desenvolvimento dos tipos móveis, por Gutenberg. A popularização da escrita desenvolveu uma cultura que possibilitou um aumento da consciência crítica, o incremento das línguas nacionais e o florescimento dos estados, rompendo a hegemonia do latim e o domínio dos mosteiros ${ }^{8}$.

A era eletricidade faz-nos ver como traduzidos em termos de informação. Estamos rumo à extensão tecnológica da consciência (McLuhan, 1996).

Ao colocar o nosso corpo físico dentro do sistema nervoso prolongado, mediante os meios elétricos, nós deflagramos uma dinâmica pela qual todas as tecnologias anteriores - meras extensões das mãos, dos pés, dos dentes e dos controles de calor do corpo e incluindo as cidades como extensões do corpo - serão traduzidas em sistemas de informação (McLuhan, 1996, p. 77).

Segundo McLuhan, as tecnologias anteriores à elétrica eram parciais e fragmentárias, enquanto que a elétrica é total e inclusiva. E no trecho seguinte podemos encontrar semelhança com o pensamento Chardiniano, quando McLuhan afirma que "um consenso ou uma consciência externa se faz agora tão necessário quanto a consciência particular" (McLuhan, 1996, p. 78).

McLuhan reflete sobre o futuro, onde a questão da unidade é levantada. O problema da relevância do computador em nossa vida é por ele sublinhada. A tradução do nosso sistema nervoso em tecnologia abre as portas para a transferência de nossa consciência para o mundo do computador. É a utopia de programar a consciência para que ela não se deixe dominar pelo entorpecimento e a alienação narcísica provocada pelas ilusões do mundo do entretenimento quando ele faz com que a humanidade seja confrontada consigo mesma, mas projetada em seu próprio arremedo (McLuhan, 1996, p. 81). Questiona:

\footnotetext{
Se a obra da cidade é o refazimento ou a tradução do homem numa forma mais adequada do que aquela que seus ancestrais nômades realizaram, por que não poderia a tradução, ora em curso, de nossas vidas sob a forma de informação, resultar numa só consciência do globo inteiro e da família humana? (McLuhan, 1996, p. 81).
}

8 José Luiz Braga trata desses três grandes processos interacionais no seu artigo: "Mediatização como processo interacional de referência". 
Em seguida, McLuhan retoma algumas considerações sobre os efeitos sociais de uma tecnologia, como o do entorpecimento e aponta para possíveis tratamentos para os sintomas que se apresentam nocivos a nós. Para ele, tanto os meios como as tecnologias nos ampliam e prologam. Elas, segundo ele, constituem cirurgias coletivas realizadas no corpo social, sem preocupação com os anestésicos. Caso as intervenções necessitem ser realizadas, a possibilidade de contaminar todo o sistema deve estar no horizonte de possibilidades (McLuhan, 1996, p. 84).

O sistema inteiro é que muda. O efeito do rádio é visual, o efeito da fotografia é auditivo. Qualquer impacto altera as "ratios" de todos os sentidos. [...] Nenhuma sociedade teve um conhecimento suficiente de suas ações a ponto de poder desenvolver uma imunidade contra suas novas extensões ou tecnologias. Hoje começamos a perceber que a arte pode ser capaz de prover uma tal imunidade (McLuhan, 1996, p. 84).

Pode-se perguntar sobre os efeitos da internet em nossos sentidos, já que é um meio que envolve tanto a audição quanto a visão. A humanidade centrou as suas tecnologias principalmente entre os sentidos auditivo e visual.

A reflexão sobre a automação pontua a revolução industrial que esta traz na era da eletricidade. Com ela, os empregos desaparecem e reaparecem os papéis complexos. O longo exercício de ênfase na pedagogia e na ordenação dos dados é questionado com a possibilidade de recuperação imediata da informação. Acabam as qualificações do mundo do trabalho, bem como as matérias do mundo do ensino. Entretanto, esse continua a existir. A automação está colocando em pauta novas profissões para o trabalho, cujo futuro consiste em ganhar a vida na era da automação. Rompem-se as dicotomias entre cultura e tecnologia, entre arte e comércio, entre trabalho e lazer.

Tendo em vista que a era da informação exige envolvimento simultâneo de todas as nossas faculdades, descobrimos que os momentos de mais intensa ocupação de nossa atenção são aqueles nos quais encontramos maior lazer (McLuhan, 1996). No entanto, cabe precisar que tal não acontece como efeito direto de tecnologias, mas a partir da geração de um sem número de outras possibilidades que se vinculam a invenções sociais de uso das tecnologias. Afirma Braga que os "valores sociais que levaram à invenção de tal ou qual tecnologia 
são superados ou modificados por usos não previstos no gesto da inovação tecnológica"9.

O conceito de sociedade em rede aparece no horizonte das preocupações do pensador canadense.

Um dos aspectos principais da era elétrica é que ela estabelece uma rede global que tem muito do caráter de nosso sistema nervoso central. Nosso sistema nervoso central não é apenas uma rede elétrica; constitui um campo único e unificado da experiência (McLuhan, 1996, p. 390).

Na era eletrônica, há uma fusão entre energia e produção e informação e aprendizado. O mercado e o consumo tendem a formar um corpo único com o aprendizado, o esclarecimento e a absorção da informação. Essa é, segundo McLuhan, uma era da iluminação (McLuhan, 1996).

Sobre os computadores, ressalta que, embora sejam altamente especializados, ainda carecem de muita coisa para que se estabeleça um processo de inter-relação com a consciência. Naquele momento, constatava que eles podem chegar a simular o processo da consciência. Do mesmo modo, a rede elétrica global já começava a simular as condições de nosso sistema nervoso central. Não obstante, mesmo um computador consciente ainda seria uma extensão de nossa consciência (McLuhan, 1996).

Como se pode ver, em nenhum momento o conceito de midiatização foi explicitamente tematizado. A realidade semantizada por McLuhan não recebeu a qualificação de midiatização. Entretanto, podemos ver que ele pensou adiante, antevendo o futuro cujos inícios estamos vivendo. As profecias de McLuhan não se realizaram no final dos anos 1960 e início dos anos 1970. Contudo, hoje, deve-se reconhecer a sua importância no estabelecimento das bases que permitem realizar uma exegese adequada para o processo social hoje vivido pela humanidade.

\section{Uma primeira opinião}

Essa realidade permite diversas interpretações, todas partindo do fato de que a sociedade se constitui por meio da comunicação. O conteúdo da comunicação é a expressão da vida dessa sociedade: passado, presente, futuro, histórias, sonhos etc. $O$ resultado é o compartilhamento de vivências entre as

9 Precisão realizada em conversa com o autor em 25/08/2014. 
pessoas de todas as gerações. O processo comunicacional possibilita os avanços progressivos da sociedade, sempre em níveis cada vez mais complexos.

O processo comunicacional é um dos exemplos acabados do chamado pensamento sistêmico. Entende-se por pensamento sistêmico uma nova forma de abordagem que compreende o desenvolvimento humano sobre a perspectiva da complexidade. Para percebê-lo, a abordagem sistêmica lança seu olhar não somente para o indivíduo isoladamente, mas também considera seu contexto e as relações aí estabelecidas. Isso não significa um abandono ou desprezo pelo micro, que aparecem fenomenologicamente no cotidiano. As duas visões se completam na contemplação da realidade. A visão sistêmica não pode ser marcada por nossa crítica do momento presente ou por nossas expectativas e desejos para o futuro, reduzindo a acuidade visual do perceber o que efetivamente está acontecendo ao nível do cotidiano. Esses dois estribos, muito embora comportem riscos, exigem articulação e tensionamentos para assegurar a superações de tais riscos. Essa interação entre as duas visadas tem se mostrado muito produtiva. Braga ${ }^{10}$ diz que Lucien Goldmann, propõe isso como método sistemático (em que o que se prendeu ou hipotetizou no geral abrangente pode ser testado e desenvolvido no caso a caso e vice-versa). $\mathrm{Na}$ medida em que os autores que preferem uma ou outra abordagem desenvolvam uma agonística entre suas perspectivas, crê ele que a área de Comunicação pode gerar um conhecimento significativo e bastante resistente à falibilidade ${ }^{11}$.

Pensar sistemicamente exige uma nova forma de olhar o mundo, o homem, e, consequentemente, exige também uma mudança de postura por parte do cientista, postura essa que propicie ampliar o foco e entender que o indivíduo não é o único responsável por ser portador de um sintoma, mas, sim, que existem relações que mantêm esse sintoma. Um mapa sistêmico é uma expressão gráfica dos inter-relacionamentos entre os diversos elementos em jogo nos processos sociais.

O mapa sistêmico que se vai aqui desenhar e analisar procura mostrar a sociedade na sua dinâmica de comunicação, evidenciando a relação entre o contado e o resultado; mais, verificando a assertiva inicial de que o processo comunicacional envolve, no todo, um processo de pensamento sistêmico.

O relacionamento da mídia com os processos de significação e com os processos socioculturais expressa a realidade e se dá no âmbito do que se denomina "marco dos processos midiáticos". Esses dois movimentos, além disso,

10 José Luiz Braga, Professor do Programa de Pós-Graduação em Ciências da Comunicação da Universidade do Vale do Rio dos Sinos, São Leopoldo, RS.

11 Em conversa com autor em agosto de 2014. 
interagem para a construção do sentido social, levada a cabo por indivíduos e sociedades.

São os meios eletrônicos (a mídia) que desempenham o papel de dispositivos enunciadores da informação. Nela se percebe um processo de significação que contempla a construção do discurso nas suas diversas configurações - tanto construções verbais como não verbais (por imagens, gestos e ações). No marco das possibilidades comunicativas, a mídia escolhe determinados conceitos, imagens e gestos com os quais elabora um processo enunciativo que permite a comunicação com e para a sociedade. No mesmo movimento, a mídia desenvolve uma dinâmica de processos socioculturais. A importância dessa dinâmica reside no fato de que qualquer processo significativo incide diretamente nas relações sociais. Essas, por sua vez, condicionam, determinam e influenciam tanto os processos de significações como a mídia na sua atuação comunicativa. As relações, inter-relações, correlações, conexões e interconexões acontecem num movimento de dupla mão entre os três polos dos processos midiáticos. Isto é, a mídia, os processos de significação, os processos socioculturais influenciam-se mutuamente gerando o fenômeno dos processos midiáticos.

A circulação de mensagens acontece de forma imediata entre o polo da emissão e o polo da recepção ${ }^{12}$. O mesmo processo acontece midiaticamente. A mídia se apropria de conteúdos e os trabalha por meio dos processos de significação e socioculturais. Esse movimento complexo acontece dentro dos contextos dos processos midiáticos.

A circulação também se estrutura em conexões e interconexões que se desenrolam no marco das relações que a sociedade engendra para que a comunicação aconteça com rapidez e eficácia. Os conteúdos transmitidos chegam à sociedade e seus resultados retornam para o processo de comunicação, via processos midiáticos, gerando, assim, um ambiente comunicacional mais amplo que influencia e é influenciado pelos seres humanos.

No processo de comunicação, há circulação de conteúdos que, elaborados socialmente, produzem resultados práticos e simbólicos. Isso aparece nos distintos elementos em jogo no processo de comunicação: na sociedade, na comunicação, nos processos midiáticos. Existem relações diretas, imediatas, e

12 Sobre a questão da circulação, ver, entre outros, os trabalhos de José Luiz BRAGA, principalmente: Circuitos versos campos sociais. In: MATTOS, Maria Ângela; JANOTTI JUNIOR, Jeder e JACKS, Nilda. Mediação \& Midiatização. Salvador: EDUFBA e Brasília: Compós, 2012, p. 31- 52. Antônio FAUSTO NETO. Circulação além das bordas. In: FAUSTO NETO, Antônio e VALDETTARO, Sandra (Orgs.). Midiatización, Sociedad y Sentido: diálogos entre Brasil y Argentina. Rosario, Argentina: Departemtno de Ciências de la Comunicación, Universidad Nacional de Rosário, p. 2-15, 2010. 
relações indiretas, mediadas pela mídia nos seus processos de significações e sociais, conforme aparece no mapa sistêmico abaixo.

שigura 1: Mapa Sistêmico

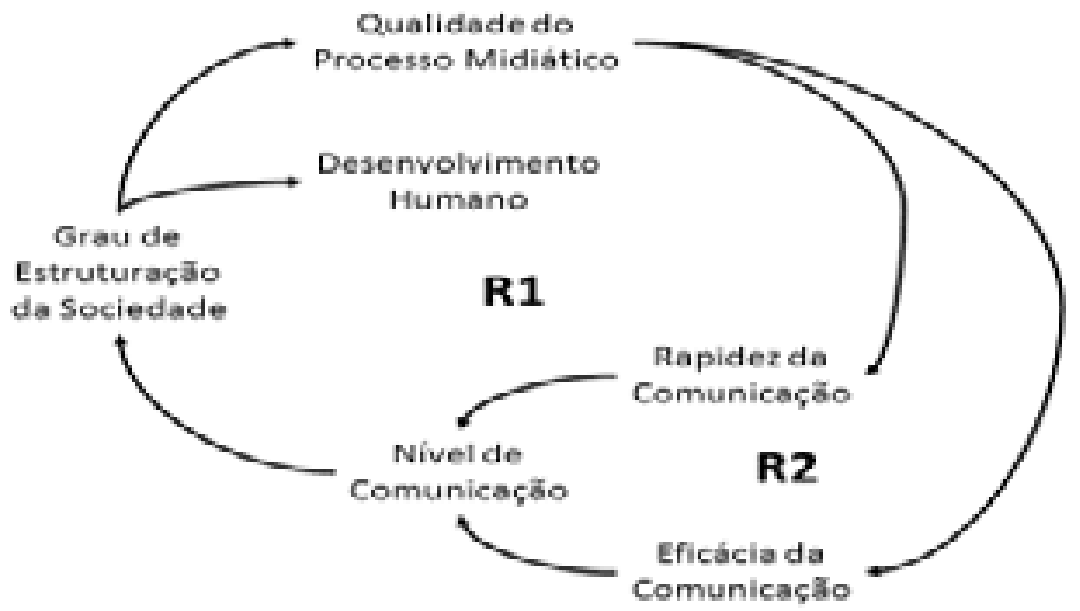

Fonte: o autor.

Este mapa permite uma leitura sistêmica dos processos midiáticos em desenvolvimento hoje. O aumento do nível da comunicação resulta em uma maior estruturação da sociedade e, dessa forma, incrementa o desenvolvimento humano assim como a qualidade do processo midiático, os quais colaboram para o aumento da rapidez e eficácia da comunicação, aumentando, da mesma forma, o nível de comunicação.

São as relações R1 e R2 que expressam os processos de circulação, cuja complexidade vai dando origem a uma sociedade em midiatização. Didaticamente, pode-se afirmar que R1 inicia o processo e que R2 torna-se um ponto de chegada e de partida para que a circulação continue, num movimento onde não se pode mais identificar o seu início. O resultado é a constituição de um ambiente novo que possibilita um novo modo de ser no mundo, como se verá a seguir.

Com o advento da tecnologia digital, essas inter-relações se tornaram complexas e se ampliaram, criando uma nova ambiência. O processo humano de comunicação é potencializado, na sociedade contemporânea, pela sofisticação de seus meios eletrônicos. Desse modo, os inter-relacionamentos comunicacionais, bem como os processos midiáticos, ocorrem no cadinho cultural da midiatização. A realidade da sociedade em midiatização supera e 
engloba as dinâmicas particulares que essa engendra para se comunicar. $O$ meio social é modificado. A tela de fundo, o marco dentro dos quais interagem as dinâmicas sociais, é gerada pela assunção da realidade digital. A virtualidade digital traz como consequência a estruturação de um novo modo de ser no mundo.

A sociedade em midiatização constitui, nessa perspectiva, o cadinho cultural onde os diversos processos sociais acontecem. Ela é uma ambiência, um novo modo de ser no mundo, como dissemos, que caracteriza a sociedade atual. As inter-relações recebem uma carga semântica que as coloca numa dimensão radicalmente nova, qualitativamente distinta em relação ao modo de ser na sociedade até então.

Comunicação e sociedade, imbricadas na produção de sentido, articulam-se nesse crisol de cultura que é resultado da emergência e do extremo desenvolvimento tecnológico. Mais do que um estágio na evolução, ele é um salto qualitativo que estabelece o totalmente novo na sociedade. 0 resultado desse movimento cria um ambiente (que chamamos de sociedade em midiatização) que configura para as pessoas um novo modo de ser no mundo, pelo qual os meios não mais são utilizados como instrumentos possibilitadores das relações pessoais, mas fazem parte da autocompreensão social e individual.

A identidade é construída a partir da interação com os meios. A pessoa não é um "eu" que usa instrumentos como extensão de seu corpo, mas um indivíduo que se autocompreende como um ser que preza as suas relações e conexões por meio dos instrumentos tecnológicos de comunicação.

A sociedade em processo de midiatização é maior, mais abrangente, que a dinâmica da comunicação até agora levada a cabo na chamada sociedade dos meios. Não é somente a comunicação que é potencializada, istoé, não são apenas as possibilidades de comunicação, por meios tecnológicos extremamente sofisticados, que caracterizam o contexto atual, mas a sofisticação tecnológica, amplamente utilizada pelas pessoas desde a mais tenra idade, cria um novo ambiente matriz que acaba por determinar o modo de ser, pensar e agir em sociedade. A esse ambiente matriz designamos de "sociedade em midiatização".

A midiatização abrange dois movimentos simultâneos e dialéticos. De um lado, ela é fruto e consequência das relações, inter-relações, conexões e interconexões da utilização pela sociedade dos meios e instrumentos comunicacionais, potencializados pela tecnologia digital. De outro, ela significa um novo ambiente social que incide profundamente nessas mesmas relações, inter-relações, conexões e interconexões que constroem a sociedade contemporânea. A sociedade é em midiatização. O ser humano é em midiatização. Isso, hoje, sublinhe-se, configura um novo modo de ser no mundo. 
Esse é o substrato cultural no qual se movem os diversos grupos sociais no mundo. A sociedade erigida nesses movimentos é uma sociedade em processo de midiatização.

\section{Referências}

BASTOS, Marcos Toledo. Medium, media, mediação e midiatização. A perspectiva germânica. In: MATTOS, Maria Ângela; JANOTTI JUNIOR, Jeder; JACKS, Nilda (Orgs.). Mediação \& Midiatização. Salvador: EDUFBA; Brasília: Compós, p. 5378, 2012.

CHARDIN, Pierre Teilhard de. El Porvenir del Hombre. Madrid: Taurus, 1962. Communication Research Trends. Theological and Religious Perspectives on the Internet. V. 31, n. 1, 2012.

FAUSTO NETO, Antônio (Org.). Midiatização e Processos Sociais - aspectos metodológicos. Santa Cruz: Edunisc, 2010.

GOMES, Pedro Gilberto (e outros). Estudos de comunicação: transversalidades epistemológicas. São Leopoldo: Ed. Unisinos, 2010.

Da Igreja Eletrônica à Sociedade em Midiatização. São Paulo: Paulinas, 2010.

HJARDARD, Stig. The Mediatization of Culture and Society. London \& New York: Routledge, 2013. Tradução brasileira pela Editora da Unisinos, São Leopoldo, 2014.

HERMES - Une revue de l'Institut des sciences de la communication du CNRS (ISCC) $n$. 25 - Le dispositif - entre usage et concept (Numéro coordonné par Geneviève JACQUINOT-DELAUNAY et Laurence MONNOYER), 1999.

MARCONDES FILHO, Ciro. Prefácio à edição brasileira. In: LUHMANN, Niklas. A realidade dos meios de comunicação. São Paulo: Paulus, 2005.

MARTIN BARBERO, Jesus. Dos meios às Mediações. Rio de Janeiro: Editora da UFRJ, 1997.

MATTOS, Maria Ângela; JANOTTI JUNIOR, Jeder; JACKS, Nilda (Orgs). Mediação \& Midiatização. Salvador: EDUFBA; Brasília: Compós, 2012.

MCLUHAN, Marshall. Os meios de comunicação como extensões do homem. São Paulo: Cultrix, 1996. 
REIS, Abel. Problematizando o conceito de bios midiático. In: Sessões do Imaginário, ano 11, n. 15, 2006.

SODRÉ, Muniz. Antropológica do Espelho. Petrópolis: Vozes, 2010.

WOLF, Tom. Introdução. In: MCLUHAN, Marshall. McLuhnan por McLuhan. Rio de Janeiro: Ediouro, 2005.

Recebido em: 26/10/2015

Aceito em: 5/11/2015

Endereço do Autor:

Pedro Gilberto Gomes <pedrogilberto28@hotmail.com>

Universidade do Vale do Rio dos Sinos

Av. Unisinos, 950 - Cristo Rei

93022-000 - São Leopoldo, RS - Brasil 